\title{
Population dynamics and spatial structure of human-biting mosquitoes, inside and outside of houses, in the Chockwe irrigation scheme, southern Mozambique
}

\author{
J. Derek Charlwood ${ }^{1,2}$, Gracieta A. Macia ${ }^{1}$, Maria Manhaca $^{1}$, Bruno Sousa $^{3}$, Nelson Cuamba ${ }^{1}$, \\ Mauro Bragança ${ }^{3,4}$ \\ ${ }^{1}$ Instituto Nacional de Saúde, Ministério da Saúde, CP 264, Maputo, Mozambique; ${ }^{2}$ DBL Centre for Health \\ Research and Development, 57 Thorvaldensvej, Fredriksberg -C 1871, Denmark; ${ }^{3}$ Centro de Malária e \\ Doenças Tropicais, UEB, IHMT, UNL, Lisbon, Portugal; ${ }^{4}$ Faculdade de Medicina, Universidade de Lisboa, \\ Lisbon, Portugal
}

\begin{abstract}
Focal control of malaria vectors, a potentially cost-effective alternative to conventional control, requires a spatio-temporal understanding of the mosquitoes. Trapping of African malaria vectors has generally been limited to inside houses making distribution estimates dependent on the location of dwellings. The development of tent-traps to sample outdoor biting mosquitoes has enabled more independent estimates. Here we describe both temporal and spatial variation in mosquito movements in an irrigation project village in southern Mozambique. Six hundred and ninety-three tent-trap collections (525 of which were paired with light-trap collections), 552 exit collections and 391 collections of mosquitoes resting inside houses were undertaken from March 2005 to April 2006. Fifteen species of mosquito were collected (five exclusively as larvae). Mansonia africana was the most common finding, numbers being greatest away from the village. Only Anopheles funestus, An. tenebrosus and Culex quinquefasciatus were collected in greater numbers in light-traps compared to tent-traps. Among the common mosquitoes, correlations in numbers of mosquito collected in paired tent and in light-traps were significant for all but An. tenebrosus. Inverse distance weighting was used to produce raster density maps of the most common mosquitoes. All species, with minor variations, in both hot and cool seasons, were collected in greatest numbers close to the edges of the village where water suitable for larval development was available. All exophilic anophelines species tested negative for sporozoites. It is suggested that focal control of larvae, applied by the villagers themselves, could be a suitable alternative to conventional control in this and similar villages.
\end{abstract}

Keywords: tent-trap, focal control, vector distribution, malaria, Mozambique.

\section{Introduction}

Many diseases follow the so-called $80 / 20$ rule, in that $80 \%$ of the disease occurs in $20 \%$ of the population at risk (Woolhouse et al., 1997). Under such circumstances targeted or focal control may be costeffective (Carter et al., 2000). If simple rules can be used to locate the $20 \%$ of people or places that suffer most exposure to disease, without the need for extensive studies, this would facilitate such control efforts. For diseases such as malaria, an understanding of the temporal population dynamics of the vectors has long been used to determine the optimal time to conduct anti-vector measures such as indoor residual spraying (IRS). In addition to temporal variation, malaria trans-

\footnotetext{
Corresponding author:

J. Derek Charlwood

Instituto Nacional de Saúde

Ministério da Saúde, CP 264, Maputo, Mozambique

Tel: +258 825257934

E- mail: jdcharlwood@gmail.com
}

mission is spatially structured (Carter et al., 2000). The advent in recent years of remote sensing and geographical information systems (GIS) and global positioning systems (GPS) has enabled accurate spatial mapping of human and animal populations to be undertaken at the same time as determining the temporal population dynamics. These systems are now often applied to the spatio-temporal mapping of the distribution of mosquitoes and other disease vectors (Capina et al., 2009) and, in some countries, used to plan and execute control measures (Kelly et al., 2010). Studies so far undertaken indicate that mosquito populations vary almost as much in space as they do in time (Smith et al., 1995; Ribeiro et al., 1996; Magbity and Lines, 2002; Cano et al., 2010). To date, however, almost all studies of mosquitoes in Africa, where most malaria is transmitted, have been concerned with indoor biting mosquitoes (Smith et al., 1995; Ribeiro et al., 1996). Thus, the estimated spatial structure of the measured mosquito populations is dependent on where people build their houses (Smith et al., 1995). 
This emphasis has partly been because most malaria is transmitted inside houses and partly because of the difficulty of measuring densities of outdoor biting mosquitoes. Outdoor biting vectors that are less affected by control techniques deployed inside houses will increasingly comprise an important fraction of residual transmission. The use of simple tent-traps (Govella et al., 2009; Kampango et al., 2010; Charlwood et al., 2011, 2012) enables densities of outdoor biting mosquitoes to be measured. Tent-traps also enable a more rigorous, uniform, spatial sampling structure to be performed compared to sampling where houses are built of different materials.

Techniques that target outdoor and animal biting mosquitoes are being developed. It has, in this connection, been pointed out that "the development and implantation of these novel techniques will require vastly improved understanding of the ecology of mosquitoes generally, rather than just the handful of highly efficient anthropophagic (malaria) vectors that have been the overwhelming focus of research thus far" (Kiware et al., 2012). Indeed, the understanding of the ecology of other mosquitoes that may be vectors of emerging diseases is slight. We, therefore, used tenttraps to obtain information on the dynamics and spatial distribution of the outdoor-biting fraction of mos- quitoes, in addition to the indoor one, from an African village. We were able to develop a simple rule of thumb for focal village control, and we report on the dynamics of the different mosquito species that occurred in the the study area, the village of Massavasse and surroundings in the Chockwe irrigation scheme in southern Mozambique.

\section{Methods}

\section{Study site}

The $1 \times 2 \mathrm{~km}$ rectangular village of Massavasse $\left(24^{\circ}\right.$ $62^{\prime} \mathrm{S}$ latitude; $33^{\circ} 108^{\prime} \mathrm{E}$ longitude), is situated in the Chockwe irrigation scheme (the largest in Mozambique). On the outskirts of the village houses are generally mud walled with thatch roofs, whilst in the middle of the village, cement houses dating from colonial days, are to be found. The village, which is divided into five separate localities, has a health post where residents can receive treatment for malaria. As might be expected from an irrigation scheme, the surrounding area is flat and treeless. Rice is the primary crop grown. Two feeder canals border the northern and southern edges of the village (Figure 1, Google Earth $\mathrm{kmz}$ file). People buy their water for irrigation

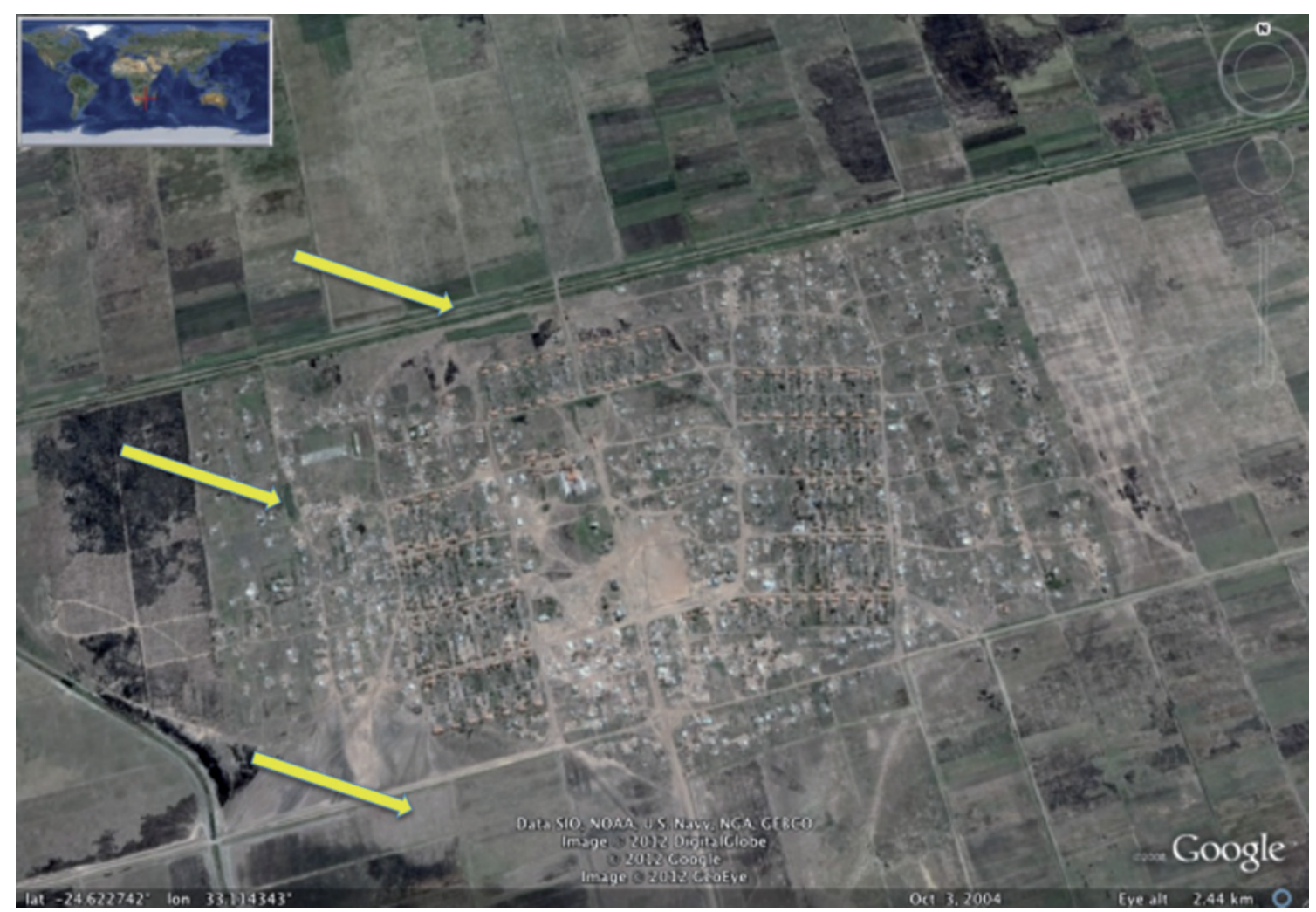

Fig. 1. Google Earth file Massavasse.kmz showing Massavasse village, Chockwe district, Gaza province, Mozambique including some of the different water bodies searched for mosquito larvae during the study. 
from the Chockwe Water Authority, which monitors the supply to these canals. Water is drawn from these canals into smaller subsidiary canals, many of which leak. Overall, this gives rise to a variety of water bodies that might be suitable for mosquito larvae; from large irrigated fields with young rice, through seepage ditches with emergent vegetation to small open puddles. In addition to the great variety and abundance of potential breeding sites there are a variety of potential hosts, in addition to humans, in the village. Cattle and goats are commonly kept in open corrals at night and many people keep chickens, ducks and dogs. Anopheles funestus is the only malaria vector of any importance in the village even though a number of other anophelines (including An. arabiensis) occur there. Other culicines, such as Mansonia africana, Ma. uniformis, Culex tritaeniorhynchus, Cx. quinquefasciatus and Aedes scataphogoides, are also common.

The area is semi-arid with an average of less than $600 \mathrm{~mm}$ of rain per year. The climate is characterised by two seasons, one hot and wet (October-April) and one dry and cold (May-September). The clay content of the soil is relatively high so that, despite the relatively low amounts of rain, surface water accumulates in the village by the end of the rainy season. In May 2006, the indoor walls of approximately $80 \%$ of houses in the village were sprayed with the Bendiocarb insecticide bendiocarb (http://www.epa.gov/oppsrrd1/REDs/factsheets/0409fact.pdf).

At the start of the study in 2003, the village was mapped using hand-held GPS (Garmin E-Trex) units. Materials used in house construction were noted and inhabitants censused. Other potential determinants of exposure to disease, such as the house condition and related variables such as the use of bednets, were also noted. Corrals, for the overnight stabling of cattle, were mapped and the numbers of adult and juvenile cows per corral recorded. Information on water supplied to the two main canals that provide irrigation water for the fields surrounding Massavasse were kindly supplied by the Chockwe Water Authority as were data on rainfall from three nearby villages for the period concerning the present study.

\section{Mosquito collection}

Four adult mosquito collection methods were applied: CDC miniature light-traps, Furvela tenttraps, collection of indoor resting mosquitoes and exit collection. Together the trapping techniques enabled us to determine which species were endophagic (biting inside houses) or exophagic (biting outside) and which were endophilic (resting inside) or by inference exophilic (resting outside).

CDC miniature light-traps were used throughout the study to collect host-seeking females indoors. The traps were placed approximately $1.5 \mathrm{~m}$ off the ground at the foot of a bed in which a human host slept under an un-impregnated mosquito net. In cement houses a specially constructed stand holding the battery and supporting the trap at the requisite height off the ground, was used. In other houses the traps were hung from suitable roof beams. Furvela tent-traps were used to collect host-seeking mosquitoes outdoors from 2004 (Govella et al., 2009; Kampango et al., 2010; Charlwood et al., 2011, 2012). The trap uses a standard CDC light-trap without the light or lid suspended on the outside of the tent, using string or wire, horizontally $2 \mathrm{~cm}$ from the door of the tent, which at that point is left open to allow for the dispersion of host odours. Two-man bell tents, each with a single occupant, were used. Tent-traps were run from 19:00 hours to daybreak. Indoor resting mosquitoes from representative houses from each of the five sub-divisions of the village were collected in 2004 and 2005 . Torches and manual aspirators were used to locate and collect these mosquitoes. Finally, exit collection of mosquitoes leaving houses during the dusk exodus was undertaken. A mosquito-netting curtain was suspended over the open door of selected houses and mosquitoes were caught using a manual aspirator as they attempted to leave (Charlwood, 2011). Collection was started a few minutes before sunset and continued until it was too dark to see the mosquitoes without a torch.

In 2003 (when only light-traps were used), houses for collection were drawn from a random list based on the initial housing survey. In subsequent years the village was divided into a series of 16 quadrats, each approximately $250 \times 500 \mathrm{~m}$ in size. Tent-trap samples were run each month as close to the centroid of each quadrat as possible. The house nearest to this position was chosen for indoor sampling with light-traps. This generally meant that the light-trap collection was within $30 \mathrm{~m}$ of the tent-trap sample. For tent-trap samples that were taken in the middle of the village, which did not have houses in the vicinity, or in the fields away from the village, this distance was considerably greater. A number of ad hoc tent-trap collections were also undertaken in uninhabited areas away from the village. Sampling for larvae was undertaken using standard scoops in a variety of water bodies including the canals, flooded rice fields, in ponds at the outskirts of the village and pools within the village. 
Following collection, the adult mosquitoes were killed by freezing and separated into species or species groups. Anophelines were identified using the keys of Gillies and DeMeillon (1968) and Gillies and Coetzee (1978). Particular care was taken to identify An funestus group members. Dr Ralph Harbach of the British Museum kindly identified voucher specimens of the non-anopheline adult mosquitoes. Samples of members of the An. gambiae complex and An. funestus were subsequently identified by the polymerase chain reaction (PCR) methodology using the protocols and primers of Scott et al. (1993) and Weeto et al. (2004). Females were further subdivided into "unfed", "part-fed", "fed", "semi-gravid" or "gravid" categories according to the appearance of their abdomen as described by Detinova (1962). Adult anopheline females were subsequently tested, in pools of 10 , for the presence of Plasmodium falciparum circumsporozoite protein by ELISA using the protocols of Wirtz (1987).

\section{Statistical analysis and mapping protocols}

The R software, version 2.11.1 (R Foundation for Statistical Computing) (http://www.r-project.org) was used to compute most mathematical and statistical operations. Census and collection data were entered into Excel spreadsheets (Microsoft Corporation ${ }^{\odot}$, Redmond, WA, USA). Data verification was performed by confirmation of a haphazard sample of $10 \%$ of the datasheets. In addition, the five highest recorded numbers collected for each mosquito species were verified from the original data sheets. Subsequently, data were imported to a MySQL database (Oracle Corporation ${ }^{\odot}$ ) (http://www.mysql.comR) where spatial coordinates from houses, their mode of construction and entomological data, were merged and used to produce new datasets based on means by collection site. Normality was assessed using the Kolmogorov-Smirnov normality test for log-transformed data (Lilliefors, 1967). Once normality was determined, Pearson correlation was applied to determine the relationship between trap types or for correlating vector density and water in the canals or precipitation. When log transformation was not sufficient to normalise data, Spearman correlation was used instead.

We analysed differences between tent and light-trap and stratified across seasons. For these analyses, collections were divided into the hot/wet season (October to April) and the cool/dry season (May to September). Assessment of the normality of data was a prerequisite for parametric testing. When normality of data failed a non-parametric approach, the Wilcoxon signed rank test (Rosner et al., 2006), was used. Given the possibility that the light in the light-trap may affect mosquito numbers, due to its inherent attractiveness to some species but not to others, and that house construction (which varies according to location in Massavasse) may influence entry rates of mosquitoes (and hence estimated densities), estimates for tent-trap collections were used to provide spatial estimates of all species. Nevertheless, because of their importance as possible vectors of disease, density estimates from light-traps were also produced for An. funestus, An. arabiensis and $C x$. quinquefasciatus.

Spatial coordinates for houses, obtained with a handheld GPS and merged datasets obtained via MySQL queries, allowed density mapping of mosquitoes with ArcGIS 9.3.1 software ESRI ${ }^{\odot}$, Redlands, CA, USA. Preliminary spatial analyses were conducted using kernel estimates to provide an estimate of tent-trap and light-trap numbers of catches for each species. Once preliminary analyses suggested clustering tendencies, inverse distance weighting (IDW), which is a multivariate interpolation analysis, was applied according to Shepard's formula (Shepard, 1968) and parameterised for 20 points for light-traps and 15 points for tenttraps to produce an interpolation of vector density raster. The number of points used for each trapping method was dependent on the number of samples for each trapping method, which were considerably greater for light-traps than tent-traps.

Jenks natural breaks (Jenks, 1963; Brewer and Pickle, 2003), which minimise each class's average deviation from vector count means while maximizing each class's deviation from the means of the other classifications, were used to generate maps. This system reduces the variance within classes whilst maximizing the variance between classes. Five natural breaks were used to produce the maps. Fewer breaks produced relatively uniform maps in which density distribution was less distinct, whilst it was considered that a larger number of breaks led to over-interpretation of the data.

Williams (1937) described a way to obtain more consistent results by comparing the geometric means of insect catches rather than arithmetic means. This is most conveniently done by summing the logarithms of the numbers instead of the numbers themselves. If any of the numbers in the series is zero it has been found practical to add one unit to all the captures in the series and so deal with $\log (n+1)$ instead of $\log n$. The use of the logarithms prevents the swamping of the results in a series of observations by very high numbers on a single night. It also gives a more normal distribution of departures from a mean. As a result it is 
possible to apply the statistical formulae for standard deviation, which are not applicable to the skew curve obtained by the use of the departures of the numbers themselves from an arithmetic mean. This average, now known as the Williams mean, was determined for tent and light-traps for the most common species.

\section{Results}

Eight hundred and ninty-eight houses were recorded in the census of 2003 and 2,547 light-trap collections from 638 of these were subsequently undertaken. Six hundred and ninety-three tent-trap collections (525 of which were paired with light-trap collections), 552 exit collections and 391 collections of mosquitoes resting inside houses were also performed. Ninety-nine tent-trap collections were conducted at distances greater than $50 \mathrm{~m}$ from the nearest house in areas away from the village. Fifteen species of mosquito were identified during the study, four species exclusively as larvae (that were subsequently reared to adults), six species in both larval and adult collections and five exclusively as adults (Table 1).

All 27 An. funestus group mosquitoes examined by PCR were An. funestus s.s. (Szalanski et al., unpublished data) and all samples examined morphologically also keyed out to An. funestsus s.s, including those specimens collected away from the village (i.e. they had a single pale spot on the upper branch of the $5^{\text {th }}$ vein and no pale spot at the tip of the $6^{\text {th }}$ vein). Similarly the only member of the An. gambiae complex identified was An. arabiensis. Hence, we assumed that these were the only members of their respective groups or complexes that we collected. Unfortunately, the database of the numbers of Ma. uniformis collected from the light-traps was lost and so only a limited amount of information concerning this species will be presented.

\section{Mosquito seasonality}

The results obtained with the Williams mean approach described above for tent and light-traps for the most common species and, with the maximum number for a single trap night, is shown in Table 2. Only An. funestus, An. tenebrosus and Cx. quinquefasciatus were collected in greater numbers in lighttraps compared to tent-traps. A strong correlation was observed between the number of An. funestus collected from the 438 paired light and tent-trap collections (Spearman correlation coefficient of $0.85 ; \mathrm{P}<0.001$ ) suggesting that the two trap types are positively correlated for this vector. Additionally, no significant differences of the population means between the paired traps were found with the Wilcoxon signed rank test $(\mathrm{P}=0.136)$. Most An. tenebrosus were collected from a house at the edge of the village. The difference between the light traps and the tent-traps for An. funestus were similar for the hot and the cold seasons $\mathrm{P}=0.224$ and 0.448 , respectively), suggesting that outdoor and indoor collections were sampling the same population. This was true for individual collections of An. funestus but differed significantly for individual collections of other species. Nevertheless, the monthly means of individual collections were positively correlated. Individual light and tent-trap collections

Table 1. List of the species collected in Massavasse village, Chockwe district, Gaza province, Mozambique between 2003 and 2007.

\begin{tabular}{|c|c|c|c|}
\hline Genus & Species & Stage collecetd & Breeding site \\
\hline \multirow[t]{6}{*}{ Anopheles } & An. funestus s.l & Adult and larvae & Rice fields, canal margins, shaded water \\
\hline & An. gambiae s.l. & Adult and larvae & Animal footprints, tyre tracks, puddles \\
\hline & An. pharoensis & Adult and larvae & Rice fields \\
\hline & An. tenebrosus & Adult & Not found \\
\hline & An. squamosus & Adult & Not found \\
\hline & An. wellcomi & Adult & Not found \\
\hline \multirow[t]{2}{*}{ Mansonia } & Ma. africana & Adult and larvae & Pools with emergent vegetation \\
\hline & Ma. uniformis & Adult and larvae & Pools with emergent vegetation \\
\hline \multirow[t]{4}{*}{ Culex } & Cx. tritaeniorbynchus & Adult & Not found \\
\hline & Cx. antennatus & Larvae & Not found \\
\hline & Cx. quinquefasciatus & Adult and larvae & Wet pit latrine \\
\hline & Cx. poicilipes & Larvae & Pond and ditch at canal side \\
\hline \multirow[t]{2}{*}{ Aedes } & Ae. durbanensis & Larva & Pond and ditch at canal side \\
\hline & Ae. scatophagoides & Larvae & Pond and ditch at canal side \\
\hline Coquillottidia & Cq. aurites & Adult & Not found \\
\hline
\end{tabular}


Table 2. Williams mean and maximum number collected on a single trapping occasion of mosquitoes, by species, from paired lighttrap and tent-trap collections (light-trap data for Ma. uniformis not available).

\begin{tabular}{llccc}
\hline \multirow{2}{*}{ Genus } & \multicolumn{4}{c}{ Number of mosquitoes } \\
\cline { 2 - 5 } & Tent-trap & Light-trap & Tent-trap & Light-trap \\
\hline Species & \multicolumn{2}{c}{ Williams mean } & Maximum & Maximum \\
\hline An. arabiensis & 1.43 & 0.85 & 175 & 269 \\
An. funestus & 2.49 & 2.80 & 139 & 368 \\
An. tenebrosus & 1.07 & 0.66 & 215 & 258 \\
An. phaeroensis & 0.56 & 0.24 & 613 & 110 \\
An. squamosus & 0.34 & 0.10 & 210 & 21 \\
Cx. triteaeniorhynchus & 1.34 & 0.58 & 299 & 230 \\
Cx. quinquefasciatus & 3.18 & 2.71 & 370 & 275 \\
Ma. africana & 10.60 & 3.43 & 1,448 & 1,235 \\
Ma. uniformis & 1.83 & - & 323 & - \\
\hline
\end{tabular}

of An. arabiensis were significantly different during the hot season $(\mathrm{P}<0.001)$.

Monthly mean densities from both light tent-traps for both the hot and the cool season, and the relationship between the two types of collection, are shown for An. funestus, An. arabiensis and An. tenebrosus, in Fig. 2. With the exception of An. tenebrosus there was a significant correlation between the monthly means from paired tent and light-trap (Table 3). It was particularly strong for An. arabiensis (Pearson correlation $\mathrm{r}^{2}=0.95 ; 95 \%$ confidence interval $(\mathrm{CI}), 0.90$ 0.98). An. funestus was more common in the light-traps than the tent-traps during the first 14 months that these were used. After that, and co-incident with the spraying of the inside walls of houses with insecticide (bendiocarb) by the local authorities, the ratio of An. funestus in the light traps and the tenttrap changed from 1:0.73 before to 1: 1.7 after (Fig. 2 ). During the study, the numbers of An. funestus declined as did the numbers of the other potential malaria vector $A n$. arabiensis. The other species (that were largely exophagic and zoophilic) also declined during the study (Fig. 2).

Larvae of An. arabiensis were found in a variety of
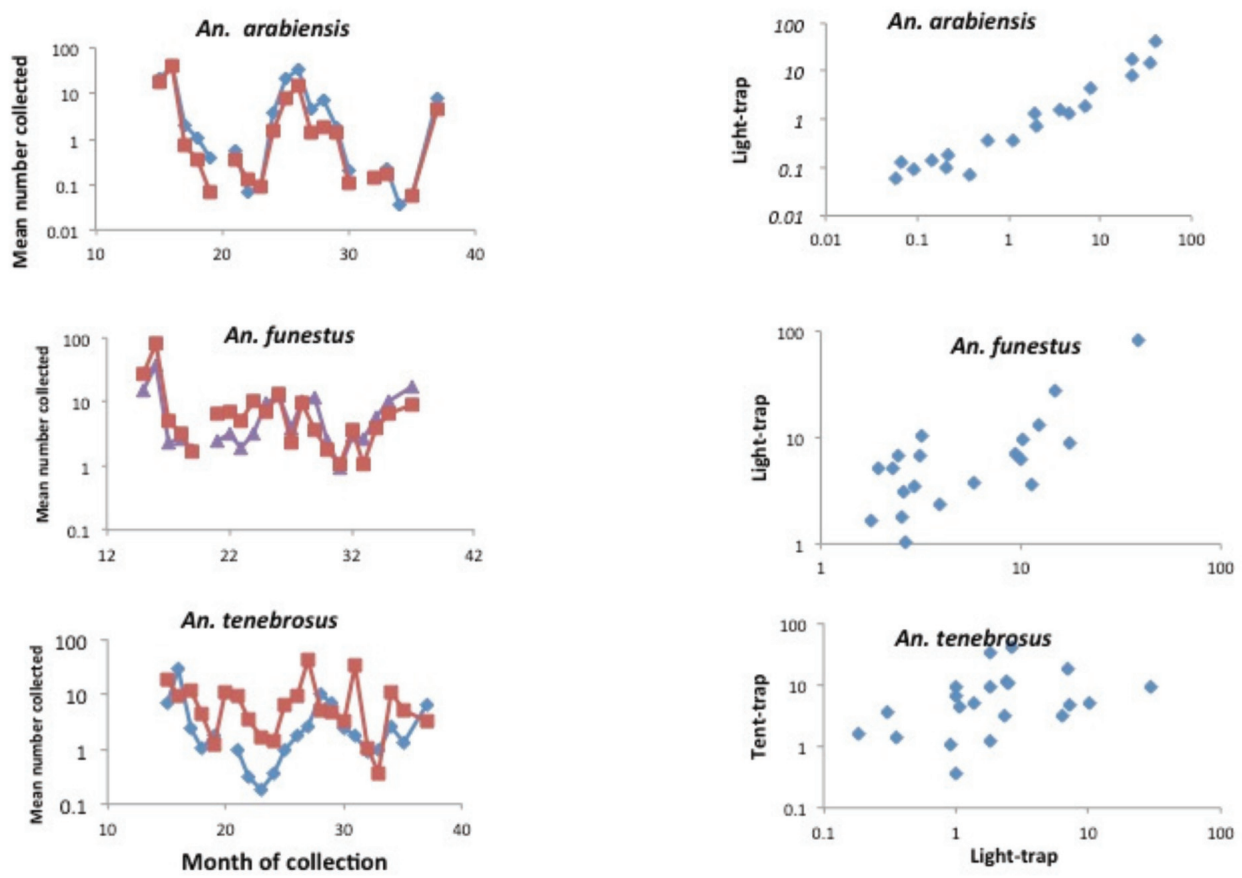

Fig. 2. Mean numbers of mosquitoes collected per collection round (24 sites per round) in the tent-traps and the light-traps by species and the association between the two trapping types. 
small to medium sized temporary rain pools within the village and in cattle hoof prints within the irrigation scheme. Larvae of An. funestus were found in irrigation channels and seepage pools bordering the canals at the edge of the village, whilst larvae of An. pharoensis, An. tenebrosus and An. squamosus were found in the rice paddy. Larvae of both Ma. africana and $M a$. uniformis were found in irrigation channels. The mean monthly number of $C x$. quinquefasciatus in tent-trap and light-trap collections and the water supplied to the Massavasse canals were correlated $(\mathrm{r}=$ $0.79 ; 95 \%$ CI, $0.52-0.92 ; \mathrm{P}<0.001$; and $\mathrm{r}=0.54$; 95\% CI, $0.1-0.80 ; \mathrm{P}=0.019$, respectively). There was, however, no apparent relationship between water supplied to the canals and collections of any of the other species.

\section{Mosquito spatial distribution}

Mapping of mosquito density was possible in the hot season for 336 unique light-trap houses and 40 tent-trap positions and during the cold season for 289 light-trap and 25 tent-trap positions. More than 20 days of collection were undertaken in approximately half of the tent-trap locations.

The spatial distribution of An. funestus, An. arabiensis, An. tenebrosus, Cx. tritaeniorhynchus, $C x$. quinquefasciatus and Ma. africana, derived from tent-trap samples within the village, are shown in Figs. $3 a-f$ for the hot and the cold season. Figs. 4a-c show the corresponding results for An. funestus, An. arabiensis and Cx. quinquefasciatus, in this case based on collections from light-traps. The highest densities of mosquitoes from both tent-traps and light-traps were greatest towards the edges of the village in both seasons, particularly close to a pond on the western edge and the seepage ditch from the lateral canal on the north-eastern edge. In the cool season, in particular, densities of $A n$. funestus were highest close to this seepage ditch north of the village. The small high-density area of $A n$. arabiensis in the middle of the village in the hot season was found to be associated with a breeding site created by the village water tank and by puddles close by. In uninhabited areas, Ma. africana and Ma. uniformis were the most common species collected and the numbers were higher than in the village (Table 4). An. funestus was also collected in these areas (Table 4).

The 552 exit collections produced 33,310 mosquitoes. Gravid and unfed females and males were the most common categories of the anophelines leaving houses at dusk (Table 5). Small numbers of both semi-

Table 3. Correlation co-efficient between monthly light-trap and tent-trap collections according to species and their $95 \%$ confidence interval $(\mathrm{CI})$.

\begin{tabular}{lcc}
\hline Species & $\mathrm{r}^{2}$ & $95 \% \mathrm{CI}$ \\
\hline An. arabiensis & 0.95 & $0.90-0.98^{*}$ \\
An. funestus & 0.77 & $0.52-0.90^{*}$ \\
An. tenebrosus & 0.40 & $-0.02-0.71$ \\
Cx. quinquefasciatus & 0.54 & $0.15-0.79 *$ \\
Cx. tritaeniorbynchus & 0.76 & $0.50-0.90 *$ \\
Ma. africana & 0.89 & $0.75-0.96 *$ \\
\hline
\end{tabular}

*Significant correlation at the $5 \%$ level

Hot season

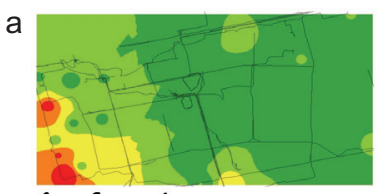

An. funestus

b

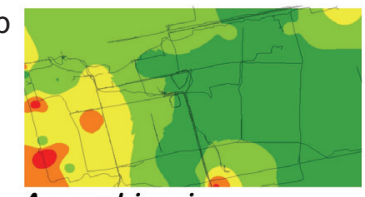

An. arabiensis

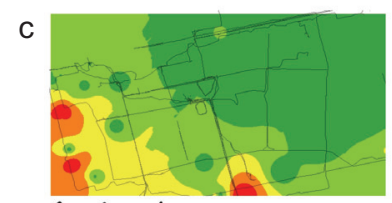

An. tenebrosus

d

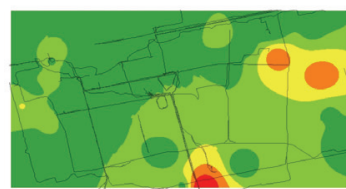

Cx. quinquefasciatus

e

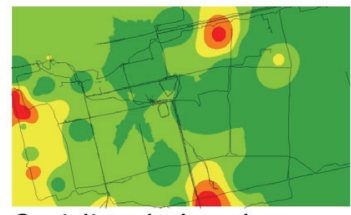

Cx. tritaeniorhynchus

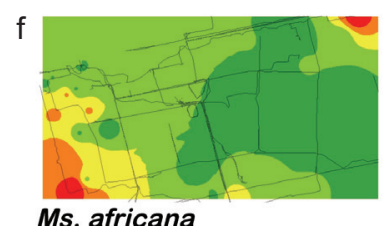

Fig. 3. Relative density distributions of mosquitoes collected from Massavasse in tent-traps in the hot season (October to April) and the cool season (May to September). The mosquito density is represented by a sliding colour scale from dark red (highest) via light red - yellow - light green to dark green (lowest). 
Hot season

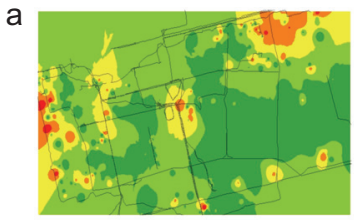

An. funestus

b

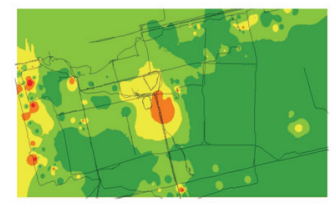

An. arabiensis

C

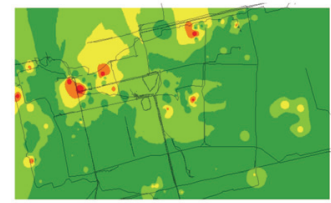

Cx. quinquefasciatus
Cool season
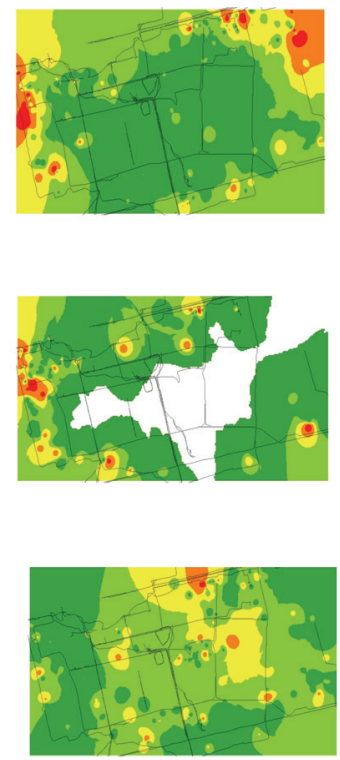

Fig. 4. Relative density distributions of mosquitoes collected from Massavasse in light-traps in the hot season (October to April) and the cool season (May to September). The mosquito density is represented by a sliding colour scale from dark red (highest) via light red - yellow - light green to dark green (lowest) white equals zero collected.

gravid and engorged females were also collected at this time. For An. funestus, An. arabiensis and Cx. quinquefasciatus female/male ratios were almost 1:1. Males of other species were also collected but at much lower numbers than females. The female mosquitoes collected while resting were generally either engorged or semi-gravid (Table 5). The proportion of the total collected differed between exit collection and tent-trap collections. Thus, although comprising $55 \%$ of the mosquitoes in the tent-trap collections and $33 \%$ of the mosquitoes from light-trap collections (excluding Ma. uniformis), Ma. africana constituted only $5 \%$ of the female mosquitoes in the exit collections. An. funestus, on the other hand, comprised $68 \%$ of the mos- quitoes in the exit collections and $74 \%$ of the mosquitoes collected while resting but only $8 \%$ of the mosquitoes from the tent-traps. The other common mosquito collected from either resting or exit collection was $C x$. quinquefasciatus. that comprised 16 and $17 \%$ of the totals caught, respectively.

Enzyme-Linked Immunosorbent Assay (ELISA) for the presence of circumsporozoite protein was positive in one out of $1,735(0.06 \%) A n$. arabiensis and 33 out of $19,904(0.17 \%)$ An. funestus tested. ELISA results were negative for 4,390 An. pharoensis, 1,318 An. tenebrosus and 840 An. squamosus.

\section{Discussion}

Here, for the first time, we provide information on the dynamics and spatial distribution of the outdoorbiting fraction of vector populations, in addition to the indoor one, from an African village. Furvela tenttraps sample exophagic mosquitoes (including members of the An. gambiae complex) and both spatial and temporal information on mosquito densities can be obtained using them. Tent-traps are particularly suitable for mapping studies since they avoid the problem of different types of house construction or number of inhabitants and can be set up in pre-defined locations, including at the edges of villages and away from human habitation. In addition to not exposing the host to mosquito bites, the Furvela tent-trap has a number of advantages over other, similar, traps for sampling outdoor biting mosquitoes. It works with any commercially available tent, takes approximately 2 min to set up in the field, uses readily available material, gives a sample in which most of the collection remains alive (and suitable for dissection) and does not require an "entry" behaviour on the part of the mosquito (since they are collected in any number before they enter the tent). Since the insects are already in a collection bag the trap does not require the person

Table 4. Mean numbers (SD) of mosquitoes collected in tent traps at different distances away from the centre of the village.

\begin{tabular}{|c|c|c|c|c|c|c|c|c|c|}
\hline $\begin{array}{l}\text { Village } \\
\text { centre }^{\mathrm{b}}\end{array}$ & $\begin{array}{l}\text { An. } \\
\text { funetsus }\end{array}$ & $\begin{array}{l}\text { An. } \\
\text { arabiensis }\end{array}$ & $\begin{array}{l}\text { An. } \\
\text { phaeroensis }\end{array}$ & $\begin{array}{l}\text { An. } \\
\text { squamosus }\end{array}$ & $\begin{array}{l}\text { An. } \\
\text { tenebrosus }\end{array}$ & $\begin{array}{l}\text { Ma. } \\
\text { uniformis }\end{array}$ & $\begin{array}{l}\text { Ma. } \\
\text { africana }\end{array}$ & $\begin{array}{l}\text { Cx. } \\
\text { tritaenioryn. }\end{array}$ & Culex spp. \\
\hline $1.05 \mathrm{~km}$ & $9.0(4.2)$ & $5.3(7.1)$ & $1.3(1.3)$ & $0.3(1.7)$ & $3.3(2.7)$ & $70.0(74.3)$ & $703(462)$ & $42.3(56.4)$ & $7.3(7.7)$ \\
\hline $0.97 \mathrm{~km}$ & $8.9(7.3)$ & $11.1(10.4)$ & $10.4(12.1)$ & $5.9(6.4)$ & $17.9(42.1)$ & $35.6(56.2)$ & $311(354)$ & 32.3 (69.9) & $9.9(11.2)$ \\
\hline $0.61 \mathrm{~km}$ & $3.5(3.9)$ & $6.5(11.2)$ & $7.6(6.3)$ & $2.7(6.5)$ & $5.0(8.5)$ & $44.8(49.3)$ & $173(179)$ & $14.5(17.3)$ & $10.0(11.1)$ \\
\hline $0.50 \mathrm{~km}$ & $9.8(8.8)$ & $6.9(9.1)$ & $3.1(5.2)$ & $3.5(5.2)$ & $9.4(8.7)$ & $30.2(37.1)$ & $140(210)$ & $29.0(28.3)$ & $5.1(7.9)$ \\
\hline \multirow[t]{2}{*}{$0.10 \mathrm{~km}$} & $2.4(3.2)$ & $3.0(7.8)$ & $0.4(0.2)$ & $0.2(0.0)$ & $1.4(7.8)$ & $6.5(5.7)$ & $25.1(34.7)$ & $4.1(5.7)$ & $11.9(13.2)$ \\
\hline & 6.4 & 7.0 & 5.5 & 3.1 & 8.8 & 37.0 & 192.4 & 21.1 & 9.2 \\
\hline
\end{tabular}

${ }^{a}$ Standard deviation

${ }^{b}$ Distance from 
Table 5. Mean $(\mathrm{SD})^{\mathrm{a}}$ numbers of the most common mosquitoes collected from 250 positive resting and 258 exit collections in Monzambique in 2005-2006 (other species comprised less than 1\% of the collection).

\begin{tabular}{lllllllll}
\hline & & \multicolumn{9}{c}{ Females } & \multicolumn{2}{c}{ Males } \\
\cline { 3 - 7 } Collection & Species & Unfed & Part-fed & Engorged & Semi-gravid & Gravid & Total & \\
\hline Resting & An. funestus & $2.9(10.9)$ & $0.6(2.9)$ & $3.4(4.6)$ & $2.7(5.2)$ & $0.5(3.0)$ & 10.2 & $1.6(2.1)$ \\
& An. arabiensis & $0.9(1.4)$ & $0.63(1.8)$ & $0.5(0.8)$ & $0.4(0.7)$ & $0.1(0.4)$ & 2.5 & $0.4(1.1)$ \\
& Cx. quinquefasciatus & $0.8(1.4)$ & $0.3(0.9)$ & $0.6(1.3)$ & $1.9(2.9)$ & $0.8(3.1)$ & 4.4 & $0.9(2.2)$ \\
& Ma. africana & $1.8(3.9)$ & $0.1(0.5)$ & $0.7(1.6)$ & $1.0(2.1)$ & $0.3(1.2)$ & 3.9 & $0.1(0.6)$ \\
Exit & & & & & & & \\
& An. funestus & $7.8(12.5)$ & $0.4(1.6)$ & $2.4(12.3)$ & $4.3(10.2)$ & $9.3(20.8)$ & 24.2 & $22.1(34.5)$ \\
& An. arabiensis & $4.1(10.4)$ & $0.1(1.6)$ & $0.6(1.7)$ & $0.7(2.5)$ & $1.6(3.7)$ & 7.0 & $8.8(14.3)$ \\
& Cx. quinquefasciatus & $2.3(4.0)$ & $0.1(0.6)$ & $0.2(0.7)$ & $1.1(3.6)$ & $2.3(4.3)$ & 6.0 & $3.2(5.3)$ \\
& Ma. africana & $3.8(8.4)$ & $0.1(0.3)$ & $0.8(1.4)$ & $0.8(1.9)$ & $0.4(2.0)$ & 5.8 & $2.0(9.8)$ \\
\hline
\end{tabular}

${ }^{a}$ Standard deviation

in the tent to do anything other than sleep. It is also suitable for determining activity patterns throughout the night since changing of the collection bag is but a few seconds' work (Kampango et al., 2010; Charlwood et al., 2011). The lack of correlation between individual paired light and tent-trap collections for species other than An. funestus may perhaps be due to zoophilic tendencies in the other species or other environmental variants. Collections of mosquitoes leaving houses at dusk provide a simple and adequate sample of endophilic mosquitoes, especially $A n$. funestus and Cx. quinquefasciatus. These exit collections are particularly suitable since they do not require any external power, only take a few minutes to complete and pose no risk to the collector.

In Massavasse, independent of collection method, densities of mosquito tended to be higher towards the edge of the village. The numbers of Ma. africana were highest away from the village. This was probably due to a combination of a large mosquito population and a wider range of attraction of the host in the tent due to the absence of other hosts in the area. Thus, with regard to mapping of Ma. africana distributions, the areas away from the village would probably have been found to be high-density ones, which could have been shown unequivocally, had sufficient collections been undertaken there. Although the densities of mosquitoes varied by season their spatial distribution was similar throughout the year. The distribution of malaria cases in Manhiça, some $100 \mathrm{~km}$ to the south of Massavasse, was similar between seasons (Abellana et al., 2008) indicating that high-risk areas remain relatively stable over time. This should facilitate focal control once such areas have been identified. In the case of Massavasse, and presumably in similar villages, the high-risk areas were at the edge of the village. Edges are known to be areas of high density for insects as well as for mosquitoes (Bidlingmayer and Hem, 1981; Charlwood and Wilkes, 1981). This may be due to the edge being closer to the sites where the adult mosquitoes first emerge. Most species were caught at higher densities in the tent-traps compared to the light-traps and all showed a marked seasonality in density. $A n$. arabiensis was collected in approximately equal numbers in tent-traps and light-traps and, as described by Gillies and DeMeillon (1968), appeared to be "indifferent" to the location of the host. The numbers of Mansonia spp. collected while resting, or exiting at dusk, were small relative to the numbers collected in the light-traps or tent-traps. Our findings indicate that although these mosquitoes were at least partially endophagic, they were exophilic and post-prandial resting mainly occured outside with mosquitoes leaving before dusk of the day following feeding. The fact that most of the An. funestus, An. arabiensis and $C x$. quinquefasciatus collected while resting were either engorged or semi-gravid indicates that they had fed during the previous night

Whilst we cannot be certain that An. funestus s.s. was the only member of the group collected in Massavasse, the behaviour of the insects within the village was, at least until the houses were sprayed, classically endophilic. This is a behavioural characteristic of An. funestus. The mosquitoes collected away from the village are especially interesting. A feral population of An. funestus has previously been described by Cavalié and Mouchet (1961) but this came from an area where the results might be obscured by the presence of other members of the An. funestus group. In Massavasse, available host biomass away from the village at night for all mosquitoes is small. Successful feeding may be restricted to the environs of the village and mosquitoes in the fields may be doomed to die an early death unless they fly to the village, or disperse to another one. 
Within the village, only An. funestus and Cx. quinquefasciatus were endophilic. Although more An. tenebrosus specimens were collected in light-traps compared to tent-traps, most of the mosquitoes came from a single house. The walls of this house were not well built and light from the trap was visible from the outside, which may have influenced the collection. Elsewhere in Mozambique, where houses have reed walls and palm thatch roofs and where people have separate kitchens, engorged and semi-gravid $A n$. funestus rarely leave at dusk as they were obsevered to do in Massavasse (Charlwood and Bragança, 2012), but the factors responsible for the difference remain unknown.

Although the numbers of An. funestus and An. arabiensis declined following the application of the insecticide, the decline observed in other (exophagic and zoophilic) species implies that the spray was not the only factor involved in this outcome. However, whether the apparent change from endophagic to exophagic behaviour in An. funestus following IRS was because the insects entering the house were killed before being caught in the light-trap, or because they refrained from entering houses in the first place, remains unknown and merits further investigation. Given the lesser amounts of water delivered in the canals in 2007 (due to people in 2006 having failed to pay their bills), it is possible that, rather than any intentional control activity, a reduction in the area of water available for the insect hydrophase was responsible for the population decline in many of the species.

At present, malaria control activities in the Chockwe region, as in the rest of Mozambique, are designed to moderate transmission by reducing adult mosquito survival through the use of insecticides as residual sprays on the walls of houses or on bednets. An. funestus resistance to the insecticides used for these activities, in particular the pyrethroids used on bednets, has been documented from southern Mozambique (Brooke et al., 2001) and this resistance now extends as far as Malawi (Hunt et al., 2010). Our data, especially the more extensive light-trap data, indicate that $A n$. funestus, the only malaria vector of any importance in Massavasse, has a limited distribution. Focal control of larvae may therefore be a suitable control technique for Massavasse and similar villages in the Chockwe irrigation scheme. Control of the An. funestus, might be obtained by the application of a larvicide such as Bacillus Bacillus thuringiensis (Bti) (Fillinger et al., 2003) (http://en.wikipedia.org/wiki/ Bacillus_thuringiensis) or more novel methods like the use of monolayers (Bukhari et al., 2011) in the seepage pools that border the main canals, since it was here that larvae were most commonly encountered. Training villagers in the use of Bti or in the use of monolayers so that they can control these mosquitoes would seem sensible. In Massavasse, monitoring of the effects of such an approach to control could easily be done by collection of mosquitoes as they leave houses at dusk.

\section{Acknowledgements}

We would like to thank the members of the SIMA team in Massavasse for their help in collecting and identifying the mosquitoes from the present study. We also thank the villagers and village leader of Massavasse for their continued co-operation in this study. Many thanks to Ralph Harbach of the Natural History Museum in London for kindly identifying the voucher specimens of mosquito and to the Chockwe Water Authority for supplying data on water and rainfall in and around Massavasse. This study was funded in part by a grant from the SIMA initiative and partly by DBL Centre for Health Research and Development, Denmark.

\section{References}

Abellana R, Ascaso C, Aponte J, Saute F, Nhalungo D, Nhacalo A, Alonso P, 2008. Spatio-seasonal modelling of the incidence rate of malaria in Mozambique. Malaria J 7, 228.

Bidlingmayer WL, Hem DC, 1981. Mosquito flight paths in relation to the environment: effect of the forest edge upon trap catches in the field. Mosquito News 41, 55-59.

Brewer CA, Pickle L, 2002. Evaluation of methods for classifying epidemiological data on choropleth maps in series. Ann Assoc Am Geog 92, 662-681.

Brooke BD, Kloke G, Hunt RH, Koekemoer LL, Temu EA, Taylor ME, Small G, Hemingway J, Coetzee M, 2001. Bioassay and biochemical analyses of insecticide resistance in southern African Anopheles funestus (Diptera: Culicidae). Bull Entomol Res 91, 265-272.

Bukhari T, Takken W, Githeko AK, Koenraadt CJM. 2011. Efficacy of Aquatain, a monomolecular film, for the control of malaria vectors in rice paddies. PLoS ONE 6, e21713.

Cano J, Descalzo MA, Moreno M, Chen Z, Nzambo S, Bobuakasi L, Buatiche J, Ondo M, Micha F, Benito A, 2006. Spatial variability in density, distribution and vectorial capacity of anopheline species in a high transmission village (Equatorial Guinea). Malaria J 5, 21.

Capinha C, Gomes E, Reis E, Rocha J, Sousa CA, do Roário VE, Almeida AP, 2009. Present habitat suitability for Anopheles atroparvus (Diptera, Culicidae) and its coincidence with former malaria areas in mainland Portugal. Geospat Health 3, 177-187. 
Carter R, Mendis KN, Roberts D, 2000. Spatial targeting of interventions against malaria. Bull World Health Organ 78, 1401-1411.

Cavalié P, Mouchet J, 1961. Les campagnes experimentales d'éradication du paludisme dans le nord de la République du Cameroon. Première partie. Les vectuers de l'épidemiologie du paludisme dans le Nord-Cameroun. Méd Trop 21, 847.

Charlwood JD, 2011. Studies on the biology of male Anopheles gambiae Giles and Anopheles funestus Giles from southern Mozambique. J Vector Ecol 36, 382-394.

Charlwood JD, Bragança M, 2012. The effect of rain storms on adult An. funestus behavior and survival. J Vector Ecol 37, 1-5. Charlwood JD, Kihonda J, Sama S, Billingsley PF, Hadji H, Verhave JP, Lyimo E, Luttikhuizen PC, Smith T, 1995. The rise and fall of Anopheles arabiensis (Diptera, Culicidae) in a Tanzanian village. Bull Entomol Res 85, 37-44.

Charlwood JD, Smith T, Lyimo E, Kitua A.Y, Masanja H, Booth M, Alonso PL, Tanner M, 1998. Incidence of Plasmodium falciparum infections in relation to exposure to sporozoite infected anophelines. Am J Trop Med Hyg 59, 243-251.

Charlwood JD, Tomás EVE, Egyir-Yawson A, Kampango A, Pitts RJ, 2012. Feeding frequency and survival of Anopheles gambiae from a rice growing area of Ghana. Med Vet Entomol 26, 263-270.

Charlwood JD, Tomás EVE, Salgueiro P, Egyir-Yawson A, Pitts RJ, Pinto J, 2011. Studies on the behaviour of peridomestic and endophagic M form Anopheles gambiae from a rice growing area of Ghana. Bull Entomol Res 101, 533-539.

Charlwood JD, Wilkes TJ, 1981. Observations on the biting activity of Anopheles triannulatus bachmanni from the Mato Grosso, Brazil. Acta Amazonica 11, 411-413.

Cuamba N, Morgan JC, Irving H, Steven A, Wondji CS, 2010. High level of pyrethroid resistance in an Anopheles funestus population of the Chokwe district in Mozambique. PLoS ONE 5, e11010.

Detinova TS, 1962. Age grouping methods in Diptera of medical importance. World Health Organisation, Geneva.

Fillinger U, Knols BGJ, Becker N, 2003. Efficacy and efficiency of new Bacillus thuringiensis var. israelensis and Bacillus sphaericus formulations against Afrotropical anophelines in Western Kenya. Trop Med Int Health 8 37-48.

Gillies MT, Coetzee M, 1987. A supplement to the Anophelinae of Africa south of the Sahara (Afrotropical region). Johannesburg: South African Institute for Medical Research.

Gillies MT, De Meillon B, 1968. The Anophelinae of Africa south of the Sahara (Ethiopian Zoogeographical Region). Johannesburg: South African Institute for Medical Research.

Govella NJ, Chaki PP, Geissbuehler Y, Kannady K, Okumu FO, Charlwood JD, Anderson RA, Killeen GF, 2009. A new tent trap for sampling exophagic and endophagic members of the Anopheles gambiae complex. Malaria J 8, 157.

Hunt RH, Edwardes M, Coetzee M, 2010. Pyrethroid resist- ance in southern African Anopheles funestus extends to Likoma Island in Lake Malawi. Parasit Vectors 3,122.

Ijumba JN, Mosha FW, Lindsay SW, 2002. Malaria transmission risk variations derived from different agricultural practices in an irrigated area of northern Tanzania. Med Vet Entomol 16, 28-38.

Jenks GF, 1963. Generalization in statistical mapping. Ann Assoc Am Geog 53, 15-26.

Kampango A, Cuamba N, Charlwood JD, 2011. Does moonlight influence the biting behaviour of Anopheles funestus (Diptera: Culicidae)? Med Vet Ent 25, 240-246.

Kelly GC, Hii J, Batarii W, Donald W, Hale E, Nausien J, Pontifex S, Vallely A, Tanner M, Clements A, 2010. Modern geographical reconnaissance of target populations in malaria elimination zones. Malar J 9, 289.

Kelly GC, Moh Seng C, Donald W, Taleo G, Nausien J, Batarii W, Iata H, Tanner M, Vestergaard LS, Clements ACA, 2011. A spatial decision support system for guiding focal indoor residual spraying interventions in a malaria elimination zone. Geospat Health 6, 21-31.

Kiware SS, Chitnis N, Devine GJ, Moore SJ, Majambere S, Killeen GF, 2012. Biologically meaningful coverage indicators for eliminating malaria transmission. Biol Lett 23, 874-877.

Lilliefors HW, 1967. On the Kolmogorov-Smirnov test for normality with mean and variance unknown. J Am Stat Assoc 62, 399-402.

Magbity EB, Lines JD, 2002. Spatial and temporal distribution of Anopheles gambiae s.l. (Diptera:Culicidae) in two Tanzanian villages: implications for designing mosquito sampling routines. Bull Entomol Res 92, 483-488.

Ribeiro JMC, Seulu F, Abose T, Kidane G, Teklehaimanot A, 1996. Temporal and spatial distribution of anopheline mosquitoes in an Ethiopian village: implications for malaria control strategies. Bull WHO 74, 299-305.

Rosner B, Glynn JR, Lee TM-L, 2006. The Wilcoxon signed rank test for paired comparisons of clustered data. Biometrics 62, 185-192.

Russell TL, Lwetoliera DW, Knols BGJ, Takken W, Killeen GF, 2013. Geographic coincidence of increased malaria transmission hazard and vulnerability occurring at the periphery of two Tanzanian villages. Malar J 12, 24.

Scott JA, Brogdon WG, Collins FH, 1993. Identification of single specimens of the Anopheles gambiae complex by the polymerase chain reaction. Am J Trop Med Hyg 49, 520-529.

Shepard D, 1968. A two-dimensional interpolation function for irregularly-spaced data. Proceedings of the 1968 National Conference, pp 517-524.

Smith T, Charlwood JD, Takken W, Tanner M, Spiegelhalter M, 1995. Mapping the densities of malaria vectors within a single village. Acta Trop 59, 1-18.

Weeto MM, Koekemoer LL, Kamau L, Hunt RH, Coetzee M, 2004. Evaluation of a species-specific PCR assay for the 
Anopheles funestus group from eleven African countries and Madagascar. Trans R Soc Trop Med Hyg 98, 142-147.

Wirtz, R. 1987. Comparative testing of Plasmodium falciparum sporozoite monoclonal antibodies for ELISA development. Bulletin WHO, 65, 39-45.
Woolhouse ME, Dye C, Etard JF, Smith T, Charlwood JD, Garnett GP, Hagan P, Hii JL, Ndhlovu PD, Quinnell RJ, Watts $\mathrm{CH}$, Chandiwana SK, Anderson RM, 1997. Heterogeneities in the transmission of infectious agents, implications for the design of control programs. Proc Nat Acad Sci 94, 338-342. 